\title{
Study on cleaning solvents using activated alumina in PUREX process
}

\author{
By Y. Arai*, H. Ogino, M. Takeuchi, T. Kase and Y. Nakajima \\ Nuclear Fuel Cycle Engineering Lab., Japan Atomic Energy Agency, 4-33, Muramatsu, Tokai, Naka, Ibaraki 319-1194, Japan
}

(Received November 26, 2009; accepted in final form December 20, 2010)

\section{Radiolytic degradation / $n$-dodecane / TBP / Solvent cleanup / Activated alumina / PUREX process}

Summary. The PUREX process is used to extract uranium and plutonium from dissolved solutions (spent nuclear fuel liquor). The extractant is $30 \%$ tributyl phosphate in $n$ dodecane, which is known to be degradable by radiation and nitric acid. Tributyl phosphate degradation products can generally be washed in alkali solutions like sodium carbonate solution; however, it is more difficult to remove $n$-dodecane degradation products using this method.

A method of cleaning solvents using activated alumina is discussed in this study. A degradation sample of $30 \%$ $\mathrm{TBP} / n$-dodecane was prepared by irradiating (1.6 MGy) with a ${ }^{60} \mathrm{Co}$ gamma-source. The degradation products were then qualitatively analyzed using a gas chromatography-mass spectrometer (GC-MS). After being irradiated the solvents were cleaned with activated alumina, and a phase separation test with performed in evaluating the cleaned solvent.

This resulted in the discovery of a procedure for the removal of $n$-dodecane degradation products of dodecanol and dodecanone, with about $70 \%$ of the degradation products, and the phase separation performance could be clearly improved through use of activated alumina.

\section{Introduction}

The PUREX process has been widely adopted as a method of reprocessing spent nuclear fuel. In the process tributyl phosphate (TBP) is used to extract uranium and plutonium while $n$-dodecane is used as the diluent for the TBP. It is known that TBP and $n$-dodecane are degraded by radiation and nitric acid $[1,2]$. The degraded products produced need to be cleaned with the degradation of TBP and $n$-dodecane . The alkali cleanup method using sodium carbonate and sodium hydroxide is commonly used to remove TBP degradation products of DBP and MBP. However, it was reported that a part of TBP degradation products can not be removed by alkali cleanup [3]. And, alcohol, ketone, and nitro paraffin derivatives are generated as the $n$-dodecane degradation products $[1,2,4]$. $N$-dodecane degradation products provide increased density and viscosity of $30 \% \mathrm{TBP} / n$-dodecane and deterioration of the phase separation behaviour $[3,5]$. $N$-dodecane degradation products are the cause of the en-

\footnotetext{
*Author for correspondence (E-mail: arai.yoichi@ jaea.go.jp).
}

trainment that takes place according to the imperfectness of the phase separation. This explain need of removing the TBP and $n$-dodecane degradation products. These degradation products accumulate in the process, and hence a cleanup method is required to remove the $n$-dodecane degradation products from $30 \% \mathrm{TBP} / n$-dodecane.

Solid adsorbents have been used as a cleanup method to remove $n$-dodecane degradation products [6-9]. J. C. Mailen studied a new solvent cleanup method that uses solid adsorbent. The results indicated that the interfacial tension and phase separation time of an ICPP solvent $(\sim 10 \%$ TBP/normal paraffin hydrocarbon) vs sodium carbonate solution could be improved with activated alumina treatment [6]. D. J. Reif reported that degraded solvents (with interfacial tension) could be improved through use of the activated alumina cleanup method [9]. S. C. Tripathi reported that activated alumina was capable of removing $n$-dodecane degradation products from $30 \% \mathrm{TBP} / n$-dodecane, and confirmed that phosphate of high molecular weight was presence in the solvent degradation products $[3,10]$.

The TBP and $n$-dodecane degradation products need to be removed from $30 \% \mathrm{TBP} / n$-dodecane because they can influence the extraction process used in the PUREX process, and hence solvent cleanup using activated alumina was examined in this study. The efficiency of cleaning the degradation solvent using activated alumina was confirmed through gas chromatograph analysis and phase separation tests.

\section{Experimental}

\subsection{Irradiation}

$30 \% \mathrm{TBP} / n$-dodecane was contacted with $3 \mathrm{M} \mathrm{HNO}_{3}$, being the assumed actual process. The degraded solvent was

Table 1. GC-MS analysis conditions.

\begin{tabular}{lc}
\hline Detector & Mass spectrometer (MS) \\
\hline Column & TC-FFAP \\
Column temperature & $60^{\circ} \mathrm{C}$ \\
Method of sample injection & Split method $(1 / 100)$ \\
Sample injection temperature & $180^{\circ} \mathrm{C}$ \\
Carrier gas & $\mathrm{He}(100 \mathrm{ml} / \mathrm{min})$ \\
Amount of sample injected & $0.2 \mu l$ or less \\
\hline
\end{tabular}


then prepared by irradiating with a ${ }^{60} \mathrm{Co}$ gamma-source. The irradiation dose was $1.6 \mathrm{MGy}$ (dose rate: $19 \mathrm{kGy} / \mathrm{h}$ ). The irradiated solvent was then analyzed with a Gas Chromatograph Mass Spectrometer (GC-MS). The solvent degradation products were identified using the GC-MS analysis results and the data base. The analysis conditions are provided in Table 1.

\subsection{Solvent cleanup procedure}

A $20 \mathrm{ml}$ irradiated $30 \% \mathrm{TBP} / n$-dodecane sample was added to a column that had been filled with $20 \mathrm{~g}$ of activated alumina. It maintained it in the column until foam was put down enough $(5 \mathrm{~h})$. The test conditions of the solvent cleanup are provided in Table 2. Two kinds of activated alumina were used in this experiment, namely KHD-24 and NKHO-24, which had been made by Sumitomo Chemical Co. Ltd. The peak of the distribution of the pore volume of KHD24 is about $0.001 \mu \mathrm{m}$ and NKHO-24 is about $0.2 \mu \mathrm{m}$ and $0.005 \mu \mathrm{m}$.

After being treated with the activated alumina the sample solvents were analyzed through gas chromatography using a flame ionization detector (GC-FID). The solvent degradation products were evaluated in this analysis. The analysis conditions of the GC-FID are provided in Table 3.

\subsection{Phase separation procedure}

Phase separation tests were conducted by shaking the phases in a separation funnel with the phase separation time being measured as the time it took for the visible globules of the dispersed phase to disappear from the interface. The test conditions of the phase separation test are shows as follows. The $3 \mathrm{M} \mathrm{HNO}_{3}$ was used for the querous phase. Unirradiated $30 \% \mathrm{TBP} / n$-dodecane and irradiated $30 \% \mathrm{TBP} / n$-dodecane (before solvent cleanup test, after solvent cleanup test) were used for the organic phase. These solutions were added to separating funnel, and amount of solutions were $5 \mathrm{ml}$. These solutions were shaking for $3 \mathrm{~min}$.
Table 2. Test conditions of solvent cleanup.

\begin{tabular}{lc}
\hline Activated alumina & NKHO-24, KHD-24 \\
\hline Amount of activated alumina & $20 \mathrm{~g}$ \\
Sample solvent & Irradiated $30 \% \mathrm{TBP} / n$-dodecane \\
Amount of sample solvent & $20 \mathrm{ml}$ \\
Test time & $5 \mathrm{~h}$ \\
Temperature & Room temperature \\
\hline
\end{tabular}

Table 3. GC-FID analysis conditions.

\begin{tabular}{lc}
\hline Detector & Flame ionization detector (FID) \\
\hline Column & TC-FFAP \\
Column temperature & $60{ }^{\circ} \mathrm{C}$ \\
Method of sample injection & Split method $(1 / 100)$ \\
Sample injection temperature & $200^{\circ} \mathrm{C}$ \\
Carrier gas & $\mathrm{He}(100 \mathrm{ml} / \mathrm{min})$ \\
Amount of sample injection & $0.5 \mu \mathrm{l}$ \\
\hline
\end{tabular}

\section{Results and discussion}

\subsection{Solvent degradation products}

The results of the CG-MS are given in Fig. 1 (unirradiated $30 \% \mathrm{TBP} / n$-dodecane), Fig. 2 (irradiated $30 \% \mathrm{TBP} / n$ dodecane), and Table 4 . The main TBP degradation product was butanol, and $n$-dodecane degradation products were alkanes (hexane, heptane, octane, etc.), alcohol (dodecanol and long-chain alcohols) and ketone (dodecanone). The mass spectrum of the nitro grope was detected at retention time of about $27 \mathrm{~min}$. D. J. Reif reported the probable mechanism that TBP and $n$-dodecane are bonded nitro grope $[3,4,10]$. The identified solvent degradation products were similar to the results of previous analysis [2,4]. It was assumed that the peak of DBP detected at $60 \%$ of the TBP's retention time [10]. However, the peak was diverted to dodecanone and a minute peak, DBP was not able to be assigned in this analysis.

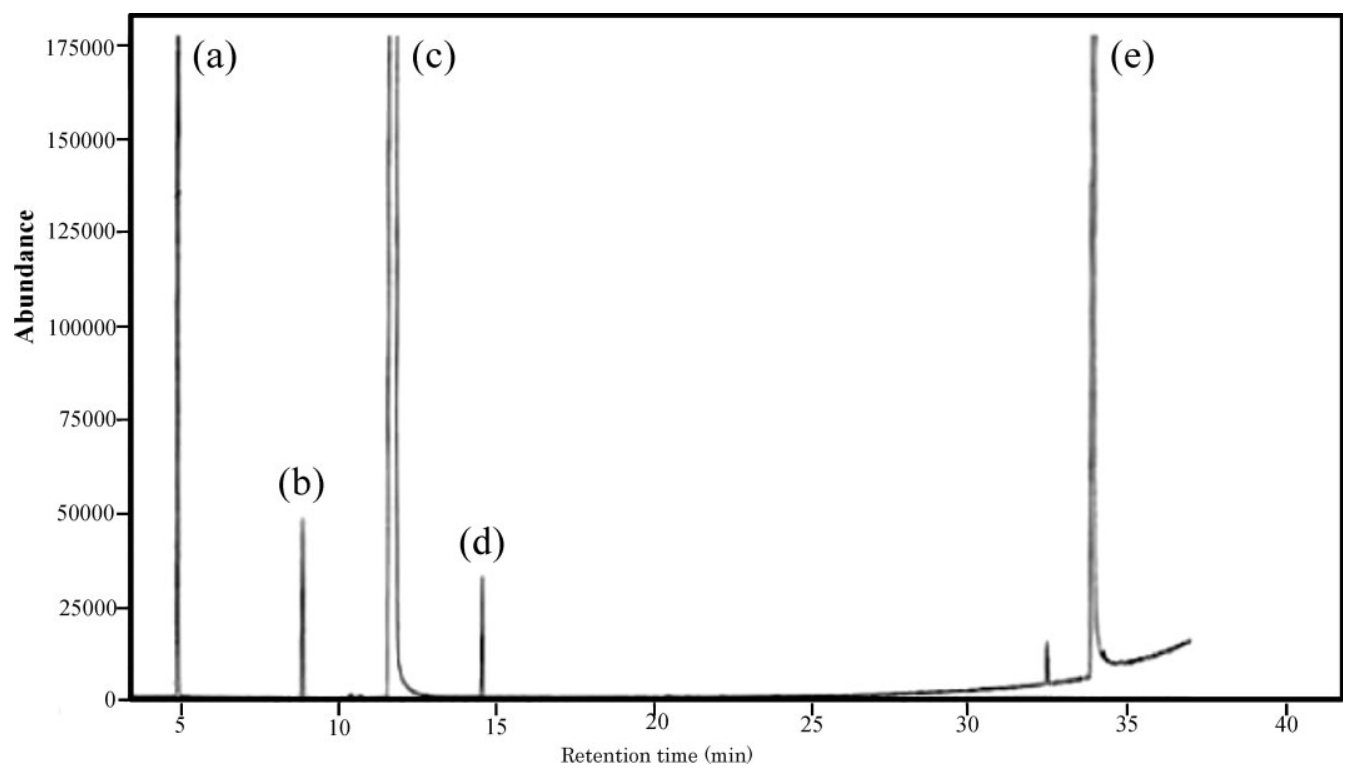

Fig. 1. Analytical results of GC-MS on $30 \% \mathrm{TBP} / n$ dodecane (Not irradiated). (a) is acetone, (b) is undecane, (c) is dodecane, (d) is tridecane and (e) is TBP. Acetone was used in the GC-MS analysis. Undecane and tridecane are refence materials used with $n$ dodedane. 


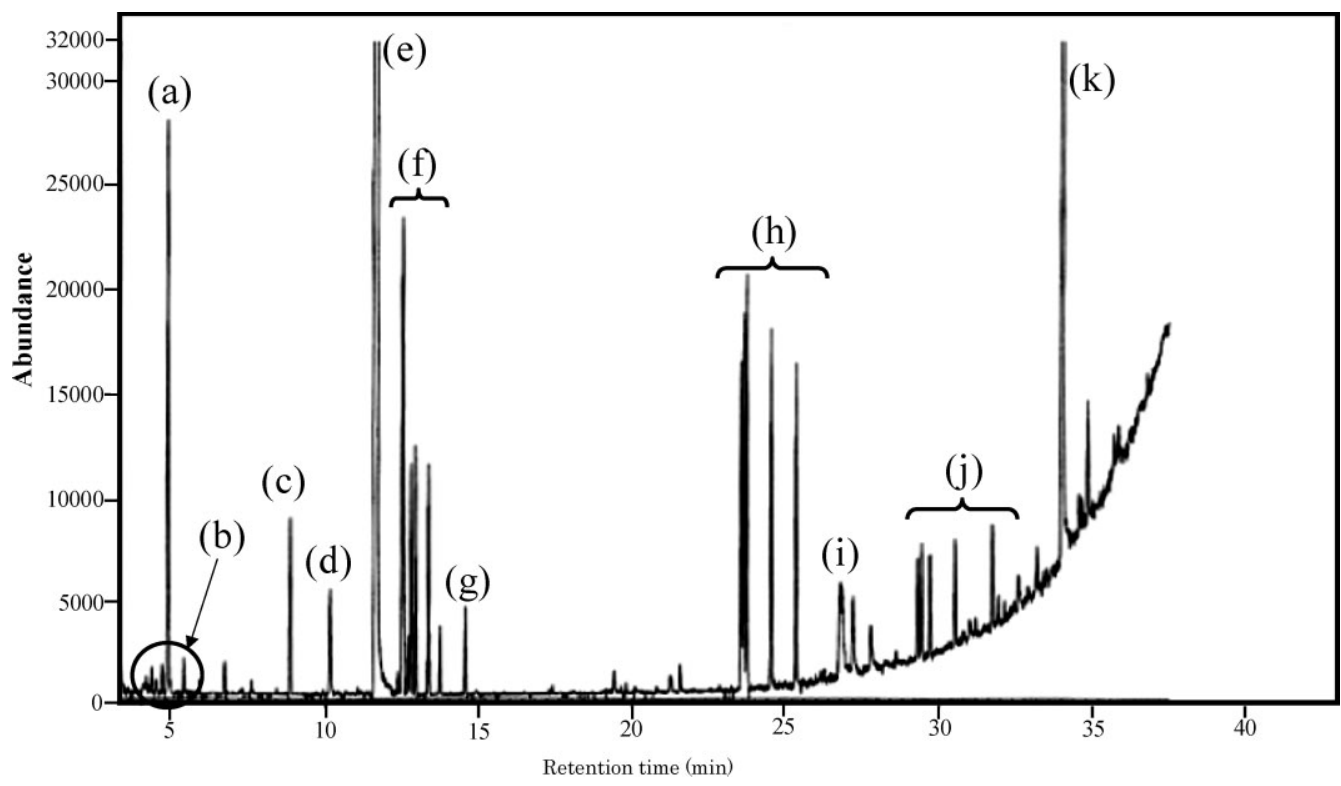

Fig. 2. Analytical result of GC-MS on irradiated $30 \%$ $\mathrm{TBP} / n$-dodecane. (a) is acetone, (b) are ketons (hexane, heptane, octane, nonane and decane), (c) is undecane, (d) is butanol, (e) is dodecane, (f) is dodecanol, ( $\mathrm{g}$ ) is tridecane, (h) is dodecanone, (i) is a nitro compound, (j) are long chain alchols and $(\mathrm{k})$ is TBP.

Table 4. Results of phase separation time tests.

\begin{tabular}{lc}
\hline Sample (solvent) & Separation time (s) \\
\hline $30 \% \mathrm{TBP} / n$-dodecane (unirradiated) & 20 \\
\hline $\begin{array}{l}\text { Irradiated } 30 \% \mathrm{TBP} / n \text {-dodecane } \\
\text { (before cleanup using activated alumina) }\end{array}$ & 43 \\
\hline $\begin{array}{l}\text { Irradiated 30\% TBP } / n \text {-dodecane (after } \\
\text { cleanup with activated alumina (NKHO-24)) }\end{array}$ & 18 \\
\hline
\end{tabular}

The compounds that have an influence on phase separation were selected from the results of the analysis. Dodecanol was first considered from the point of view of effect on surface activity, and the influence density on phase separation. This is because phase separation deteriorates if the density of the organic phase and the density of the aqueous phase are the same.

The solvent degradation products that influence phase separation time were presumed to be butanol, dodecanol, dodecanone, dodecanone, and nitro compounds. The densities of butanol (about $\left.0.81 \mathrm{~g} / \mathrm{cm}^{3}\right)$ and dodecanone $\left(0.82 \mathrm{~g} / \mathrm{cm}^{3}\right)$ are larger than $n$-dodecane $\left(0.75 \mathrm{~g} / \mathrm{cm}^{3}\right)$. The density of a nitro compound is generally greater than $1 \mathrm{~g} / \mathrm{cm}^{3}$. These degradation products can cause the density of the organic phase to increase. Dodecanol in particular is an emulsifying agent. Emulsifying agents have the effect of dispersing the aquerious and organic phases into each other.

\subsection{Removal of solvent degradation products}

The GC-FID results are provided in Figs. 3 and 4. It was observed the degradation products had decreased by as much

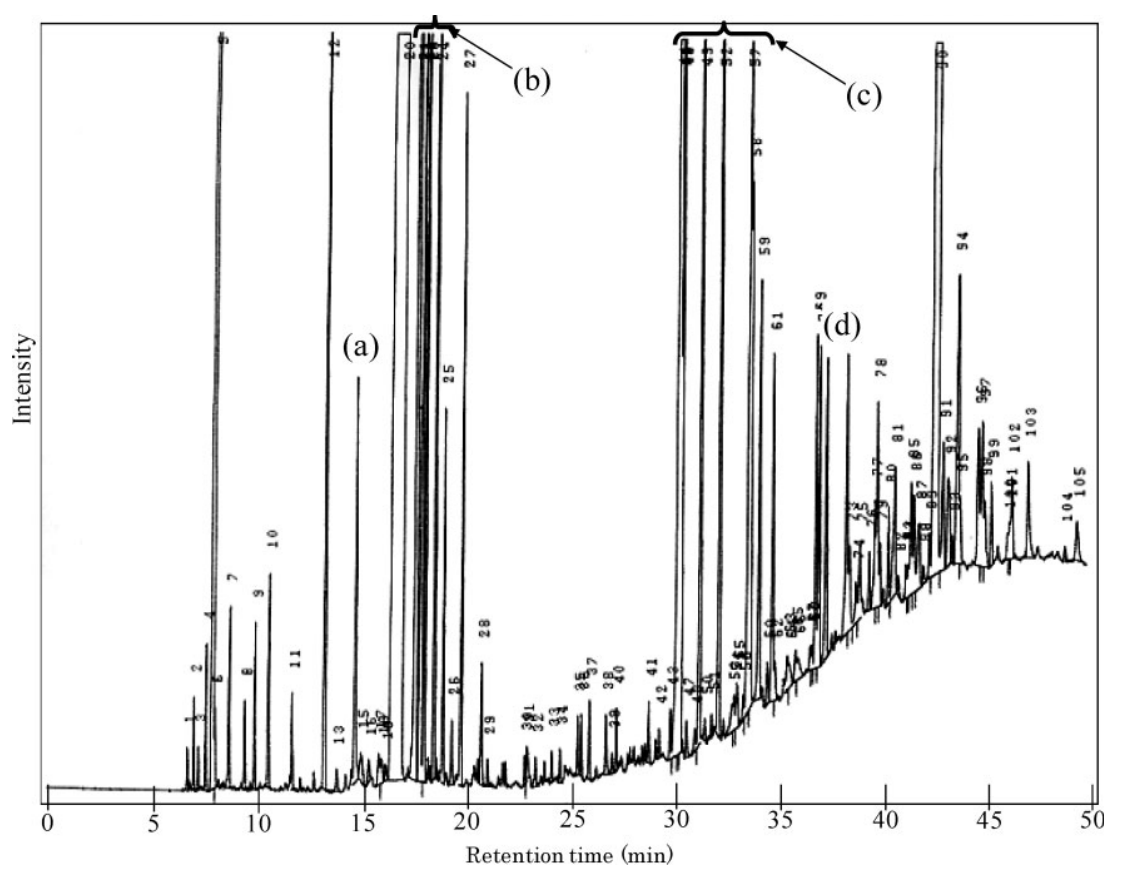

Fig. 3. Analytical result of GC-FID on irradiated $30 \% \mathrm{TBP} / n$-dodecane. (a) is butanol, (b) is dodecanol, (c) is dodecanone, (d) is nitro compound. 


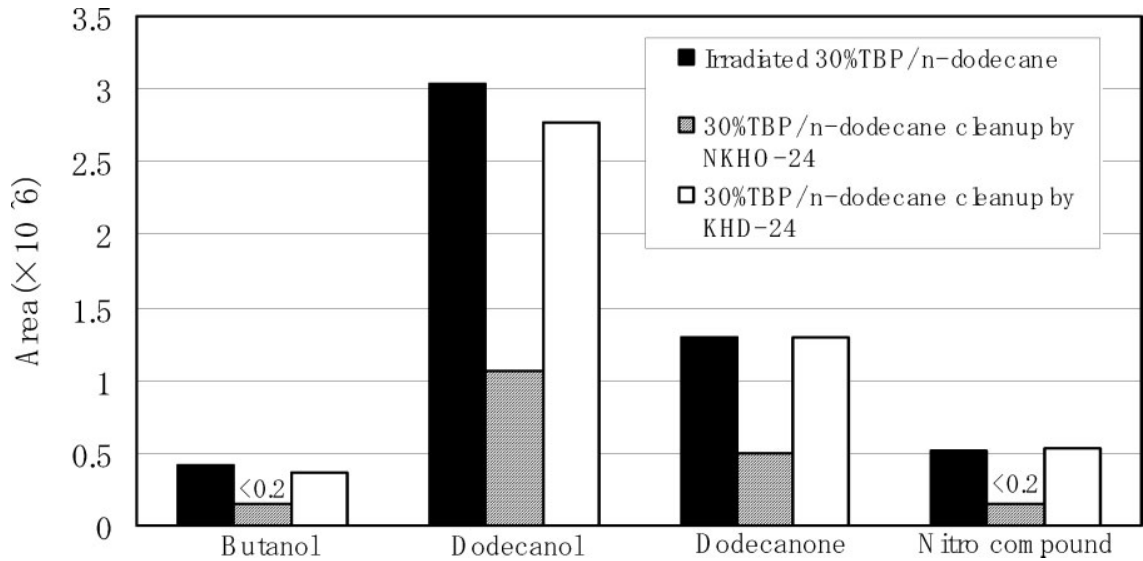

Fig. 4. Results of analysis on $30 \% \mathrm{TBP} / n$ dodecane after activated alumina treatment. as $1 / 3$, and thereby the concentrations of butanol and nitro compound had decreased to around the vicinity of less than the detectable limit value. These results revealed that the solvent degradation products that can influence phase separation were removed through the activated alumina cleanup.

It is known that activated alumina generally preferentially adsorbs polar molecules. The solvent degradation products that influence phase separation are compounds with polarity and hence it can be presumed that the degradation products were easily adsorbed by the activated alumina.

Moreover, the observation was made that the removal of the solvent degradation products was affected by differences in the pore size of the activated alumina. J. C. Mailen discovered that macroporous activated alumina most effectively regenerated solvents [8]. The results of these tests lead to the consideration that large pore size activated alumina would most effectively remove solvent degradation products from $30 \% \mathrm{TBP} / n$-dodecane. The behavior of adsorption into pores is known to differ with the size of the pore. The removal of degradation products can be expected to be improved through investigating the optimum conditions of the pore size.

\subsection{Phase separation tests}

The removal of solvent degradation products was evaluated with phase separation tests on $30 \% \mathrm{TBP} / n$-dodecane and $3 \mathrm{M} \mathrm{HNO}_{3}$. The solvent samples included unirradiated $30 \% \mathrm{TBP} / n$-dodecane, irradiated $30 \% \mathrm{TBP} / n$-dodecane, and $30 \% \mathrm{TBP} / n$-dodecane treated with NKHO- 24 .

The results of the examination indicated the phase separation time of unirradiated $30 \% \mathrm{TBP} / n$-dodecane with $3 \mathrm{M}$ $\mathrm{HNO}_{3}$ to be similar irradiated $30 \% \mathrm{TBP} / n$-dodecane treated with activated alumina, and thus a satisfactory regeneration effect. The cleaning by the activated alumina proved to be a good method of removing the solvent degradation products that can affect phase separation.

\section{Conclusion}

The results of gas chromatography analysis revealed that activated alumina can be used to remove butanol, dodecanol, dodecanone, and nitro compounds as degradation products of TBP and $n$-dodecane. About $70 \%$ of these degradation products were removed by the activated alumina. Moreover, phase separation with $3 \mathrm{M} \mathrm{HNO}_{3}$ was improved to the same level as the unirradiated solvent. Alumina of large pore size proved to be the most effective in removing degradation products, a tendency similar to the results of J. C. Mailen's research [8].

Moreover, TBP degradation products such as DBP, MBP, etc. were not detected in this analysis, making it therefore necessary to clarify how these TBP degradation products affect phase separation etc. Basic data will need to be acquired in addition to discussing an engineering scale examination to put it to practical use.

Acknowledgment. The authors are grateful to Mr. Toshihiro Kato and Mr. Tsutomu Onose of Ascend Co. Ltd. for the experimtal of solvent cleaning tests.

\section{References}

1. Tallent, O. K., Mailen, J. C.: PUREX Diluent Degradation. ORNL/TM-8814 (1985).

2. Ikeda, H., Suzuki, A.: Radiolysis of $n$-dodecane and its physical property change based on the dose in one pass through a reference HA column. J. Nucl. Sci. Tecchnol. 35(10), 697 (1998).

3. Tripathi, S. C., Ramanujam, A.: Effect of radiation-induced physicochemical transformations on density and viscosity of $30 \%$ TBP- $n$-dodecane- $\mathrm{HNO}_{3}$ system. Sep. Sci. Technol. 38(10), 2307 (2003).

4. Tripathi, S. C., Ramanujam, A.: Effects of solvent recycling on radiolytic degradation of $30 \%$ tributyl phosphate- $n$-dodecane- $\mathrm{HNO}_{3}$ system. Sep. Sci. Technol. 34(14), 2887 (1999).

5. Ikeda, H., Suzuki, A.: Empirical correlations for radiolytic degradation of $n$-dodecane density, viscosity and phase separation time. J. Nucl. Sci. Technol. 38(12), 1138 (2001).

6. Mailen, J. C., Tallent, O. K.: Cleanup of Savannah River Plant solvent using solid sorbents. ORNL/TM-9256 (1985).

7. Mailen, J. C.: Secondary Cleanup of Idaho Chemical Processing Plant Solvent. CONF-851011-9 (1985).

8. Mailen, J. C., Mattingly, C. D.: PUREX Solvent Regeneration Using Macroporous, High-Sodium Activated Alumina. ORNL/ TM-11393 (1992).

9. Reif, D. J.: Restoring solvent for nuclear separation processes. Sep. Sci. Technol. 23(12), 1285 (1988).

10. Tripathi, S. C., Ramanujam, A.: Studies on the identification of harmful radiolytic products of $30 \%$ TBP- $n$-dodecane- $\mathrm{HNO}_{3}$ by gas-liquid chromatography. II. Formation and characterization of high molecular weight organophsphates. Sep. Sci. Tecchnol. 36(13), 2863 (2001). 